\title{
Primer caso centroamericano de coccidioidomicosis
}

\author{
por \\ A. Castro" y A. Trejos"* \\ (Recibido para su publicación el 21 de mayo de 1953)
}

A medida que pasan los años, nuevos casos de granulomatosis coccidióidica descritos en diversos países hacen que se vayan ampliando los limites de distribución geográfica de la Enfermedad de Posadas.

Además de los casos observados en el área endémica del Sur de los Estados Unidos de Norte América, que sumaban ya en 1931 más de 250 (1), se han descrito, según Negroni (10), 7 en Argentina, entre los cuales se encuentia el caso de Posadas y WERNICKE.

El hecho de que también se hayan encontrado algunos casos en Europa (9), hace sospechar que existan ahí áreas de endemia semejantes a las descritas en los Estados Unidos (6) y en Argentina (12).

Recientemente Campins et al. (3 y 4) han observado los dos primeros casos de coccidioidomicosis en Venezuela y posteriormente Campins (2) reportó un 10,4 por ciento de reactores a la coccidioidina, en la encuesta epidemiológica llevada a cabo sobre 6166 personas en el Estado Lara.

En el mes de julio de 1950 nos fueron pasadas en consulta, por el Dr. Marcial Fallas Díaz, Jefe del Laboratorio de Anatomía Patológica del Hospital San Juan de Dios, unas preparaciones de un ganglio supraclavicular quie se le enviara de Honduras con el diagnóstico clínico de adenitis tuberculosa y con el fin de hacer un estudio histopatológico. La consuita la originó la presencia de unas estructuras arredondeadas que, a no dudarlo, eran de un agente de blastomicosis (Figs. 8 y 9).

Sin embargo, el pequeño número de elementos parasitarios y el hecho de no haber encontrado formas de endosporulación en la lámina que observamos, no

- Laboratorio Bacteriológico del Ministerio de Salubridad Pública.

* Laboratorio Bacteriológico del Hospital San Juan de Dios. 
nos permitió afirmar el diagnóstico micológico de Coccidioides immitis, que por exclusión no pareció el más probable, dadas las dimensiones de aquellos eic. mentos.

Solicitamos entonces a la Dra. Olga Marina Reyes que nos enviara otro ganglio del paciente, conservado en una mezcla de vaselina y parafina, con el fin de hacer el estudio micológico completo mediante inoculaciones y cultivos, que nos facultara para efectuar el dignóstico específico del parásito. Poco tiempo después llegó el paciente, cuya historia pasamos a resumir, y en quien pudimos comprobar, por los métodos adecuados, la presencia del Coccudicides immitis Rixford et Gilchrist, 1896, como ya publicamos en una nota previa aparecida en abril de 1951 (5).

A. V. A. sexo masculino, de 51 años de edad, soltero, chófer, originario de Nacaome, Honduras, y residente los últimos 24 años en el Valle de Comayagua; se ocupaba de transportar meäcadería en un camión de su propiec̀ad a través del mismo Valle. El enfermo refiere que, en diversas oportunidadss, se veía obligado a dormir dentro del camión estacionado en el camino.

En el año de 1926 se ocupó del acarreo de loza proveniente de California (?) empacada con paja; sin embargo, no creemos que este hecho tenga relación con su accidente primario que ocurrió en diciembre de 1946.

Fuera de los anteriormente apuntados, los otros antecedentes personales y los hereditarios, no parecen tener importancia en relación a su enfermedad actual. Esta se inició y siguió, en líneas generales, con los síntomas clásicis de una coccidioidomicosis primaria (tos, fiebre, dolor torácico, expectoración en algunas ocasiones hemoptoica, sudoración nocturna profusa, pérdida de peso, algias en las regiones lumbar y articulares), evolucionando luego hacia la forma granulomatosa conocida como coccidioidomicosis secundaria o progresiva.

En setiembre de 1950 llegó el paciente a Costa Rica, mostrando fístulas localizadas en ambas regiones supraclaviculares (Fig. 1) que dejaban salir una secreción sero-purulenta, a veces teñida con sangre. En el pus de estas fístulas, así como también en el esputo, fué posible demostrar la presencia de las formas parasitarias del Coccdioides immittis (Figs. 5, 6 y 7). Posteriormente apareció otra fístula en la región poplítea.

Las radiografías que se le han tomado en distintas oportunidades, durante el transcurso de la enfermedad (Figs. 2, 3 y 4), según los repories que tuvo la bondad de dar, a solicitud nuestra, el Dr. Blanco Cervantes, Directur de la Lucha Antituberculosa, muestran lo siguiente:

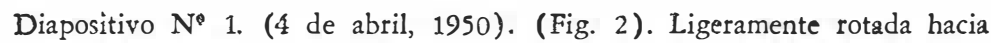
el lado izquierdo. Sombra mediastínica ensanchada en el sector superior y hacia el lacio derecho. Arco de la aorta muy marcado. Hemidiafragmas normales. Lado derecho: Sombra densa poco homogénea en la región hiliar y perihiliar que se extiende hacia la región del ángulo cardiofrénico. Hay además, extensión.de esz sombra, en forma irregular, difusa, al campo medio. En el sector superior y en el inferior, la trama se observa acentuada. Lado izquierdo: acentuación densa e irregular de la trama hiliar. Impresión: proceso de carácter fibroproductivo-ezu- 
dativo en el pulmón derecho con hipertrofia de los nódulos linfáticos hiliares, peribronquiales y paratraqueales. Hipertrofia de los nódulos lintíticos en el hilio izquierdo.

Diapositivo $\mathrm{N}^{\circ} 4$ (4 de octubre, 1950). (Fig. 3). En comparción con el diapositivo $\mathrm{N}^{\circ} 1$ se observa: acentuación densa y difusa de la trama bronquiovascular en ambos pulmones. Persistencia del ensanchamiento mediastínico e irregularidad en los contornos de éste. Acentuación densa e irregular de ambas tramas hiliares, la derecha con irradiación linear algo difusa al campo medis y al inferior. Nota: Hay marcacla regresión del proceso descrito en el pulmón derecho. Hay aumento de densidad de la trama de ambos pulmones.

Diapositivo $N^{\circ}$ 8. (1 de marzo, 1951). (Fig. 4). Parté ósea y hemidiafragmas normales. Sombra mediastínica ligeramente ensanchada en el sector supe. rior y hacia el lado derecho. Persiste acentuación densa e irrigular de abrnas tramas hiliares. La trama bronquiovascular en ambos pulmones se observa menos acentuada. Nota: hay reducción casi total del proceso descrito en el pulmón derecho e hilio izquierdo. (Firmado: Dr. R. Blanco Cervantes).

Los exámenes de heces mostraron quistes de Endamaeba coli y huevos de Tricburis tricbiura. La orina no presentó nada de anormal, aun cuando se instituyó un tratamiento de cobre coloidal, como veremos más adelante.

Con respecto al esputo, ya dijimos quie presentaba las formas típicas del C. immitis, resultando negativos tanto la investigación bacteriosıópica como los cultivos para demostras la presencia de Mycobacterium tuberculosis. Igualmente negativos por Bacilo de Koch, fueron los cultivos e inoculación al cobayo del jugo gástrico homogeneizado por el método de Petroff.

La sedimentación de los eritrocitos practicada el 14 de seticmbre de 1950 dió $27 \mathrm{~mm}$ en una hora (Cutler).

Dos recuentos totales y diferenciales de glóbulos, dieron los siguientes resultados.

14 de setiembre, 1950

17 de octubre, $19>0$

$\begin{array}{lll}\text { Hemoglobina: } & 13,2 \mathrm{~g} \% & 14,4 \mathrm{~g} \mathrm{\%} \\ \text { Eritrocitos: } & 4.250 .000 / \mathrm{mm}^{3} & 4.600 .000 / \mathrm{mm}^{3} \\ \text { Leucocitos: } & 9.200 / \mathrm{mm}^{3} & 7.450 / \mathrm{mm}^{3} \\ \text { Basófilos: } & 1 \% & 0 \% \\ \text { Eosinófilos: } & 5 \% & 3 \% \\ \text { Mielocitos: } & 0 \% & 0 \% \\ \text { Metamielocitos: } & 0 \% & 0 \% \\ \text { En banda: } & 3 \% & 2 \% \\ \text { Segmentados: } & 59 \% & 72 \% \\ \text { Linfocitos: } & 25 \% & 18 \% \\ \text { Monocitos: } & 7 \% & 5 \%\end{array}$

Las pruebas de alergia cutánea dieron:

14 setiembre 1950: Tuberculina (Mantoux) 0,01: Positiva ++++

21 noviembre 1950: Histoplasmina al $1 \%$ : Negativa

21 noviembre 1950: Coccidioidina al $1 \%$ : Positiva ++ 
Las reacciones serológicas para sífilis, practicadas en diversas oportunidades, dieron resultados variables: el 5 de abril de 1950, en la consulta externa del Hospital General de Guatemala, donde el enfermo estuvo de paso, se obtuvo una reacción de Kahn negativa y una del V.D.R.L. positiva. Nosotros encontramos lo siguiente:

14 setiembre 1950: Kahn: Negativa
31 octubre
1950:
1 diciembre 1950:

\section{VDRL: Negativa \\ " Positiva (1 dil.) \\ Positiva débil}

\section{El enfermo negó antecedentes luéticos.}

Para completar el estudio del Coccidioides, se realizaron cultivos del pus de las fístulas, en medio de Sabouraud glucosado, obteniéndose colonias con la morfología macro y microscópica típica de este hongo, como puede verse en las Figs. 15 y 14 respectivamente.

Se realizaron además inoculaciones intratesticulares en Cavia con pus de las fístulas supraclaviculares, obteniéndose al cabo de poco tiempo una orquiepididimitis supurada con presencia de las formas parasitarias típicas de $C$. immitis (Figs. 10 y 13 ).

Con respecto a estas formas, deseábamos señalar un hecho que nos parece interesante y es la presencia de esporangios unidos en pares. Estos elementos los hemos observado en cl esputo del enfermo (Fig. 7) y en el pus de testículo de cobayo (Figs. 11 y 12). Para explicar estas formas se han invocado dos hipótesis: una supone que ellas representan estados de copulación, lo cual implicaría una serie de modificaciones en los núcleos, que no han podido ser observadas (11); la otra (7) admite que sean simplemente esporangios originados a partir de clamidosporas (EMmONS)o entosporas. (NEGRONI) que permanecieron unidas por la membrana de la hifa en la cual se formaron durante la fase saprofítica. En nuestro caso ninguna de las hipótesis satisface ampliamente; la primera por lo arriba expuesto y la segunda porque sería difícil suponer que aun existieran clamidosporas en evolución en el esputo, después de varios meses de iniciada la coccidioidomicosis, y más difícil aun, en el pus de los testículos de cobayos que recibieron como inóculo, no suspensiones de cultivos, sino de material obtenido de las fístulas del enfermo. En un segundo pasaje por cobayo, los pares de esprangios aparecieron también.

Infortunadamente no tenemos ninguna explicación satisfactoria para el fenómeno y nos vemos en el caso de esperar que estudios más detallados vengan a dárnosla.

Durante el lapso de 202 días, comprendidos entre el 30 de octubre de 1950 y el 9 de mayo de 1951, en que permaneció el enfermo internado en el Servicio de Dermatología del Hospital San Juan de Dios (San José, Costa Rica) se le instituyó un tratamiento de desensibilización con coccidioidina ${ }^{1}$. Se le practica-

1 La coccidioidina nos fué suministrada por el profesor Juan F. Mackinnon del Instituto de Higiene de Montevideo, Uruguay, a quien agradecemos profundamente su gentileza 8 colaboracion. 


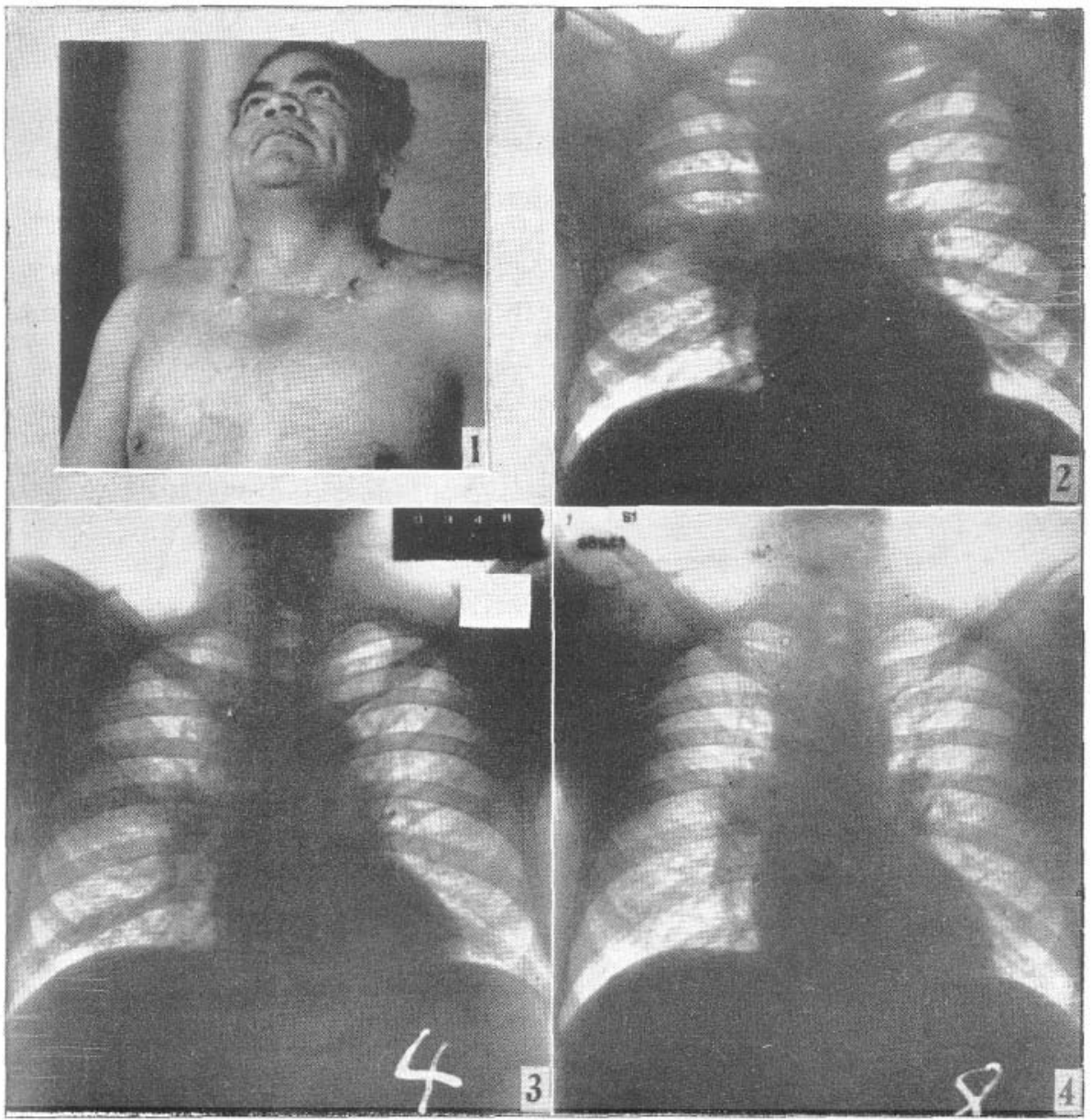

Fig. 1: A. V. A. Aspecto del cnfermo. Se aprecian las fístulas supraclaviculares en ambos lados.

Figs. 2, 3 y 4: Radiografías de A. V. A. tomadas el 14 de abril de 1950, 4 de octubre de 1950 y 1 de marzo de 1951, respectivamente. Para detalles véase el textu. 


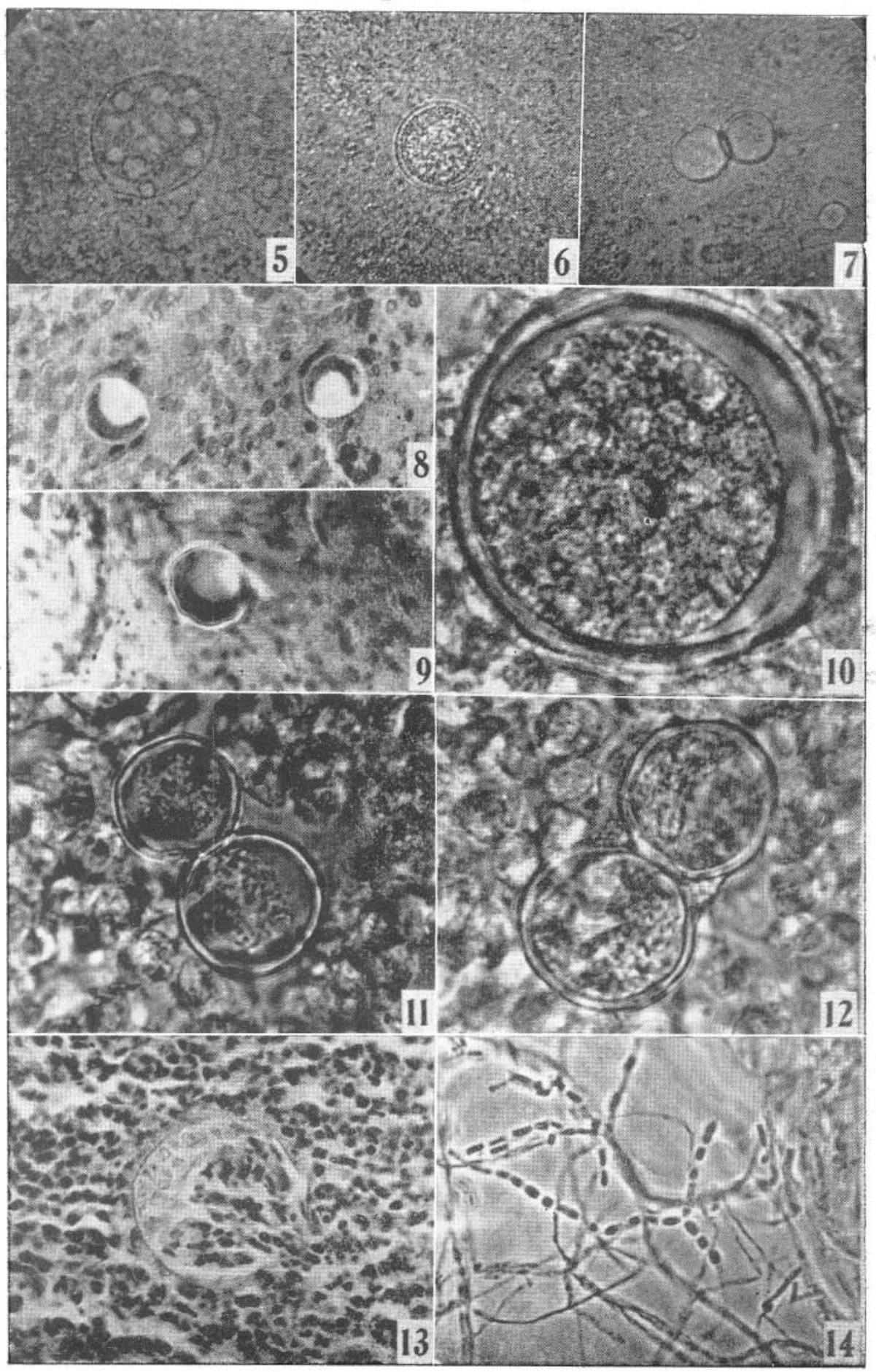




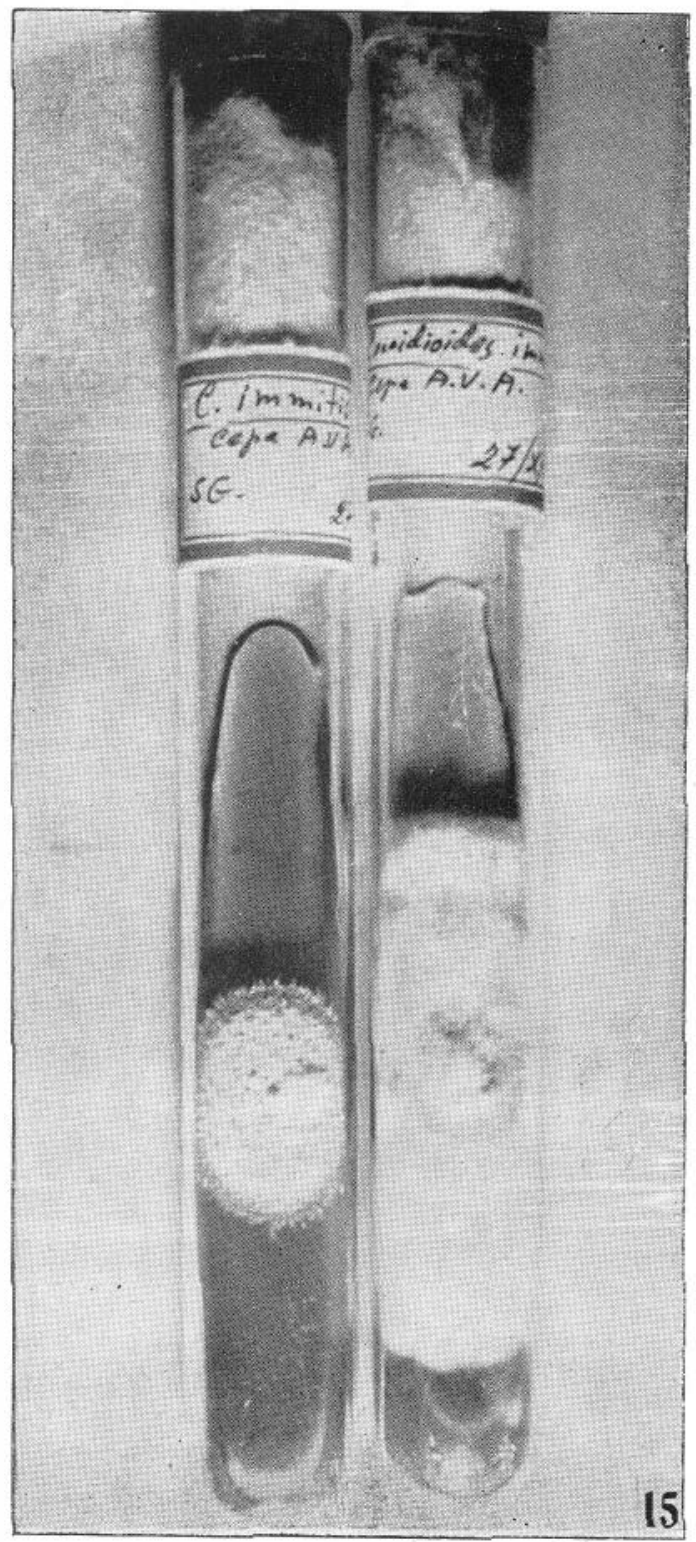

Fig. 15: C. immitis. Cepa A. V. A. Cultivos de 21/2 meses cra Sabouraud glucosado. 
ron 17 inyecciones subcutáneas con dosis progresivas que fueron de 0,10 cc de una solución al 1/10.000, a 0,80 cc de solución al 1/1.000.

Recibió también 54 inyecciones de cobre coloidal (electrocuprol) de $5 \mathrm{cc}$ cada una, por vía intramuscular.

Como tratamientos coadyuvantes para mantener el buen estado general, además del reposo, se le administró complejo $\mathrm{B}$, citrato de hierro amoniacal y aceite de hígado de bacalao.

Cuando el enfermo salió del Hospital había aumentado $3 \mathrm{~kg}$ de peso, y estaban cicatrizadas las fístulas supraclaviculares, quedando únicamente una en vías de cicatrización en la región poplítea; mostraba además las mejoras radiológicas que citamos anteriormente.

Ya listo para su publicación este trabajo, recibimos una carta del enfermo, que había regresado a Honduras, en la cual nos comunicó que la fístula de la región poplítea se encontraba abierta de nuevo y habían aparecido otros ganglios en la región supraclavicular, concomitantemente con elevaciones térmicas.

\section{DISCUSION}

Como el sabido, el aparecimiento de un caso de coccidiodomicosis evolutiva implica la existencia de varios cientos de infecciones primarias benignas o asintomáticas.

La confirmación de la etiología coccidioidomicósica del caso que acabamos de relatar nos hizo pensar, desde luego, en la existencia de muchos otros casos de primoinfección en la zona donde el enfermo contrajo su dolencia. Habiendo descartado la posibilidad de un contagio por la paja en que venía empacada la loza que el enfermo transportara en su camión, por lo remoto de esos hechos, como ya dijimos anteriormente, sólo quedaba la hipótesis de la existencia de una nueva zona de endemia, localizada en el Valle de Comayagua, Honduras, hipótesis esta a la cual ya hiciéramos referencia en nuestra nota previa (5).

Es interesante el hecho de que en algunos países centroamericanos se ha encontrado una incidencia de reactores a la coccidioidina que no pasa de 1 por ciento, como demostró TuCKer (14 y 15) en Panamá practicando intradermoreacciones en 1154 individuos. Los resultados obtenidos en Costa Rica por uno de nosotros (A. T.) y que serán publicados posteriormente, también están comprendidos en ese bajo porcentaje. Scotr (13) que realizó pruebas intradérmicas en 421 enfermos internados en el Hospital de Tela, situado en la costa Norte de Honduras, encontró, asimismo, resultados similares a los anteriores. En La Lima, Honduras, situada ya más al Sur, la incidencia es un poco mayor, pues Hoekenga y Tucker (8) obtienen 4,1 por ciento de reactores entre 300 enfermos varones del Hospital de ese lugar.

En 1951 tuvimos oportunidad de trasladarnos al Valle de Comayagua y el alto porcentaje de reactores a la coccidiodina que encontramos confirmó ampliamente nuestras sospechas. Este estudio será motivo de una publicación posterior. 


\section{RESUMEN}

19-Se relata el primer caso centroamericano de coccidioidomicosis en un hondureño que ha vivido durante los últimos 24 años, en el Valle de Comayagua, Honduras.

2?-Al describir la confirmación micológica del caso, se hacen también algunas consideraciones con respecto a la morfología del $C$. Immitis durante su fase parasitaria.

3?-Se refiere la existencia de una nueva área de endemia coccidioidomicósica en el Valle de Comayagua, Honduras.

\section{SUMMARY}

1. The first case of coscidioidomycosis in Central America, a patient from Honduras who had been living for the last 24 years in the Comayagua Valley, is described.

2. The diagnosis was confirmed by mycological cxaminations, and additional studies with respect to the morphology of $C$. immitis during its parasitic phase, were made.

3. The Valley of Comayagua, Honduras, is discussed as a new endemic area for coccidioidomycosis.

\section{REFERENCIAS BIBLIOGRAFICAS}

1. BECK, DOROTHY

1931. California Depart. of Public Healib Special Bull. No 57. Cit In MoNTEsSORI (9).

2. Campins, $\mathrm{H}$.

1950. Coccidioidomicosis: un nuevo problema de salud pública en Venezuela. Rev. Sanidad Asist. Soc., 15 (1-2) : 1-11.

3. Campins H., M. Scharyj \& R. J. Cortés

1949. Coccidioidomicosis en Venezuela. Relación dei segundo caso estudiado. Separata de Gaceta Med. Caracas, 57(19-24): $10 \mathrm{pp}$.

4. Campins, H., M. Schiaryj \& Vira Giuck

1949. Coccidioidomicosis. (Enfermedad de Posadas). Su comprobación en Venezuela.

Separata de Arch. Venezo!. Patol. Trop. Parasit. Med., 1(2) : 20 1?.

5. Castro, A. \& A. Trejos

1951. Constatación del primer caso centroamericano de coccidioidomicosis. Nota previa. Rev. Med. Costa Rica, 10(204):89-90. 
6. Dickson, Gifrord, Smith y otros, cit in Skinner, C. E., C. W. Fmmons \& H. M. TSUCHIYA

1948. Henrici's moulds, yeasts and actinomycetes. $2^{a}$ ed., XIV +409 pp. John Wiley \& Sons Inc., New York.

7. EMMONs, C. W.

1947. Biology of Coccidioides, in Nickerson, W. J. Biology of pathogenic fungi, capítulo 5, p. 71-82., Ann. Cryptogamic: et Phytopatbologici, Vol. 6., Crónica Botánica Co., Walthan, Mass.

8. Hoekenga, M. T. \& H. T. Tucker

1950. Sensibilidad a la histoplasmina y a la coccidioidina en Honduras. Informe sobre 300 enfermos. Bol. Of. Sanit. Panameric., 29 (11): 1135-1138.

9. MONTESSORI, P. P.

1941. La granulomatosi coccidioide in Europa. Mycopatbologia, 3(2):131-139.

10. Negroni, P.

1949. Estudios sobre el Coccidioides immitis Rixford et Gilchrist. II Estudio micológico de las cepas autóctonas y revisión del granuloma coccidioidal en la Argentina. Rev. Inst. Bacteriol. Malbrán, 14(1) : 128-135.

11. Negroni, P.

1949. Estudios sobre el Coccidioides immitis Rixford et Gilchrist. VIII Estudio micológico. Rev. Inst. Bact. Malbrán, 14(1) : 299-305.

12. Negroni, P., C. A. N. Daglio \& C. Briz de Negroni

1949. Estudios sobre el Coccidioides immitis Rixford et Gilchrist. V Primera investigación sobre la existencia de una endemia de coccidioidomicosis en la Argentina. Rev. Inst. Bact. Malbrán, 14(1):155-175.

13. ScotT, V.

1951. Histoplasmin, coccidioidin and tuberculin sensitivity in Honduras. Ams. Jour. Trop. Med., 31(1) : 27-32.

14. TuCKer, H. A.

1946. The coccidioidin skin test in the Panama Canal Zone. California Med., 65:52. Cit in Tucker (15) y Hoekenga \& Tucker (8).

15. TuCKer, H. A.

1950. Histoplasmin, tuberculin and coccidiodin sensitivity on the Isthmus of Panama: preliminary report of 500 patients. Amer. Jour. Trop. Med., 30(6) : 865-870. 